\title{
INVESTIGATION OF THE CORRELATION BETWEEN GRACE TWS AND SOIL MOISTURE IN SARAKHS CATCHMENT
}

\author{
F. Sabzehee ${ }^{1, *}$, V. Nafisi ${ }^{2}$, S. Iran Pour ${ }^{3}$, B. Dutt Vishwakarma ${ }^{4}$ \\ ${ }^{1}$ Geomatics Engineering, Faculty of Civil Engineering and Transportation, University of Isfahan, Isfahan, Iran - \\ sabzfarideh@gmail.com \\ ${ }^{2}$ Geomatics Engineering, Faculty of Civil Engineering and Transportation, University of Isfahan, Isfahan, Iran - vnafisi@gmail.com \\ ${ }^{3}$ Institute of Geodesy, University of Stuttgart, Stuttgart, Germany - iranpour.siavash@gmail.com \\ ${ }^{4}$ School of Geographical Sciences, University of Bristol, University Road, Bristol BS8 1SS, UK - bd.vishwakarma@bristol.ac.uk
}

\section{Commission VI, WG VI/4}

KEY WORDS: Soil moisture, GRACE, GLDAS, Total Water Storage, Sarakhs, Drought.

\begin{abstract}
:
Drought is a gradual phenomenon that may intensify with time. In fact, drought is the result of interactions between natural and human activities and usually appears in the following ways: reduction in water resources, accelerating desertification, the vegetation cover change and etc. Monitoring and predicting drought is essential for sustainable water management and mitigating socio-economic damages. The GRACE satellite mission provided monthly Earth's gravity field anomalies, which can be processed to obtain changes in Total Water Storage (TWS) content. TWS is a sum total of various compartments of water near the surface of the Earth, such as soil moisture, surface water, snow, etc. In this study, we analyze GRACE TWS and the modelled soil moisture (SM) over Sarakhs catchment in north-east of Iran, between 2003-2016. We find a time lag of 19 months between GRACE TWS and soil moisture, where both TWS and soil moisture content show negative trend over Sarakhs catchment. Our findings are similar to other reports on the water scarcity in this region.
\end{abstract}

\section{INTRODUCTION}

The hazard of drought is a complicated and a gradual phenomenon. Drought can be categorized according to meteorological, hydrological and agricultural types [12]. The phenomenon is expressed as a natural disaster which is a deficiency of precipitation during an extended period in a specific region, but it is also very much influenced by human activities, especially with groundwater exploitation. There are time lags between the lack of rain and less water in streams, rivers, lakes and reservoirs. Meteorological drought is usually based on longterm precipitation departures from normal and happens when dry weather patterns dominate an area. Hydrological drought refers to lacks in surface and subsurface water supplies. It's measured as stream flow, and as lake, reservoir, and ground water levels. Agricultural drought occurs when there is not enough soil moisture content to meet the needs of a particular crop for a specific period of time. Agricultural drought is typically evident after meteorological drought but before a hydrological drought[7]. The GRACE satellite mission records temporal variability in the Earth's gravitational field at monthly temporal resolution. The gravitational potential can be related to water mass redistribution, expressed as mm of Equivalent Water Height that represents Total Water Storage (TWS): sum of soil moisture (SM), snow water equivalent (SWE), surface water, canopy water storage and groundwater.

The GRACE satellite mission consisted of a pair of satellites in a near-polar orbit with inclination of $89^{\circ}$ and at altitudes of 300 -
$500 \mathrm{~km}$ above the Earth's surface. The two satellites are in a an along-track formation with one following the other separated by $220 \pm 50 \mathrm{~km}$. Sources of errors in GRACE include measurement errors, aliasing errors originating from the inaccurate correction of atmospheric and oceanic mass redistribution, and spatial leakage [6]. Spatial leakage is caused both by the truncation of spherical harmonics and the postprocessing filters applied to the data [5][2]. Therefore, different filtering techniques have been discussed and implemented to reduce the noise and errors in GRACE data. Filtering is essential to extract meaningful signal from GRACE fields but it affectes the signal quality via leakage and attenuation [8]. In order to restore the signal loss many method have been proposed, we choose a data-driven approach introduced by [9]. The advantage of this method is that it does not depend on models and therefore the existing errors and uncertainty in models do not propagate into the corrected GRACE products. Furthermore, it has been shown to work better than model dependent approaches over small regions (up to 63 $000 \mathrm{~km}^{2}$ ) [10].

Soil moisture observation is not readily available in our region of interest, therefore, we rely on a Land Surface Model: Global Land Data Assimilation System (GLDAS). It is forced by satellite observations and observation driven reanalysis data to yield gridded product with a spatial resolution of 0.25 degrees. Although the model has been widely used, it suffers from uncertainties associated with model assumptions and errors in input observations. 


\section{DATA}

Iran is divided into 6 major watershed regions Khazar, Persian Gulf-Oman Sea, Urmia, Markazi, Hamoon and Sarakhs. The geographical focus for this study is the Kara-Kum basin (Sarakhs) which is located in the north-east of Iran. The Sarakhs catchment has an area of about $44,000 \mathrm{~km}^{2}$ which is about $3 \%$ of the total area of the country [3]. Figure 1 shows location map of the Sarakhs catchment. We use data sets obtained from the land surface model (Global Land Data Assimilation System) GLDAS, which uses forcing data (e.g., precipitation, near-surface air temperature, specific humidity, wind speed, surface pressure and etc.), to provide estimates of land surface states (e.g., soil moisture, surface runoff, and subsurface runoff), and flux quantities (e.g., evaporation and sensible heat flux) [11]. GLDAS products are provided by four land surface models (CLM, Mosaic, Noah and VIC). In this study, GLDAS soil moisture data is used to evaluate the possible correlation between GRACE TWS and soil moisture with a temporal resolution of 1 month and a spatial resolution of $0.5^{\circ} \times 0.5^{\circ}$.

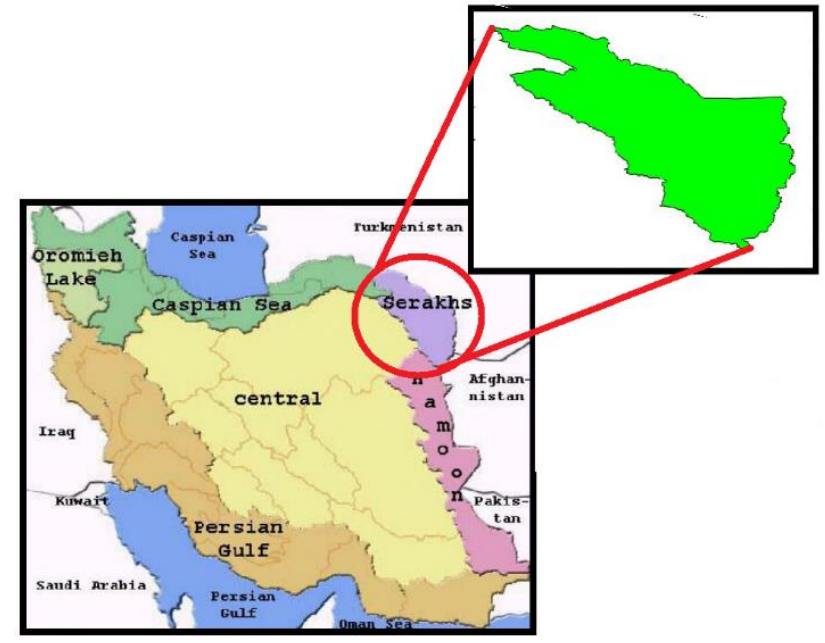

Figure 1. Location of Sarakhs Cachment.

We extract the hydrological components of GLDAS model and GRACE TWS by computing an area weighted average over the catchment.

\section{PROPOSED METHOD}

GRACE can extract realistic spatiotemporal variations of vertically integrated measurement of water storage (groundwater, soil moisture, surface water, snow water, vegetation water, etc.) at the precision of tens of $\mathrm{mm}$ of equivalent water height at large scale[4].

The TWS anomalies can be written as a sum of the changes in soil moisture $(\Delta \mathrm{SM})$, snow water equivalent $(\triangle \mathrm{SWE})$, and groundwater $(\Delta \mathrm{GW})[6]$ :

$$
\mathrm{TWSC}=\Delta \mathrm{SM}+\Delta \mathrm{SWE}+\Delta \mathrm{GW} .
$$

Consistent loss of water storage along with decaying recharge can lead to drought. Changes of the different components, including surface storage, soil moisture and groundwater can create important changes in local climate, water supply sources and agricultural production.

Soil moisture plays a valuable role for TWS in the Sarakhs catchment. Also, role of soil moisture in food security and weather and climate dynamics is undeniable. While most variations in soil moisture can be assigned to single natural disasters, changes in TWS mainly correspond to spatially extended and long-duration drought and flood periods[1]. However, the investigation of soil moisture will improve flood prediction and drought monitoring capability.

Here, we compare the GRACE total water storage data and soil moisture component simulated by GLDAS model. The time series of soil moisture composed of the top four soil layers 0-10 $\mathrm{cm}, 10-40 \mathrm{~cm}, 40-100 \mathrm{~cm}, 100-200 \mathrm{~cm}$. After drawing the soil moisture graph of the Sarakhs catchment, we have noticed that time series of soil moisture shows a negative slope but less severe than GRACE TWS. Thereafter, the cross-correlation between two time series is extracted. We obtained that soil moisture variations 19 months ahead of GRACE TWS somehow means agricultural drought happened much earlier than hydrological drought in this specific region.

\section{RESULT}

Figure 2.A shows GRACE TWS and soil moisture (2m deep below ground) changes in Sarakhs catchment during 2003-2016. The results show negative GRACE TWS and soil moisture trends with robust linear regression model(red and pink colors). Time lag helps obtain an interval of time between two related phenomena.

Figure 2.B shows that the time-lag is equal to -19 . We deleted this the time lag and plotted new trends for GRACE TWS and soil moisture. By considering the time lag, uniform changes in soil moisture can be seen but GRACE TWS still has a negative slope. Figure 3 shows the correlation between GRACE TWS and soil moisture in Sarakhs catchment. The results indicate that there is an agreement between GRACE TWS and soil moisture over Sarakhs (61.11\%). Our analysis shows that the soil moisture changes are happening earlier than GRACE TWS changes (19 months). By applying this time-shift, both signals have coincided and there can be a meaningful relationship between them.

It will be essential to understand that changes in TWS is related to many parameters that one of them is soil moisture. Therefore, we cannot conclude that the investigation of one parameter alone is sufficient to justify the occurrence of the drought or not. 

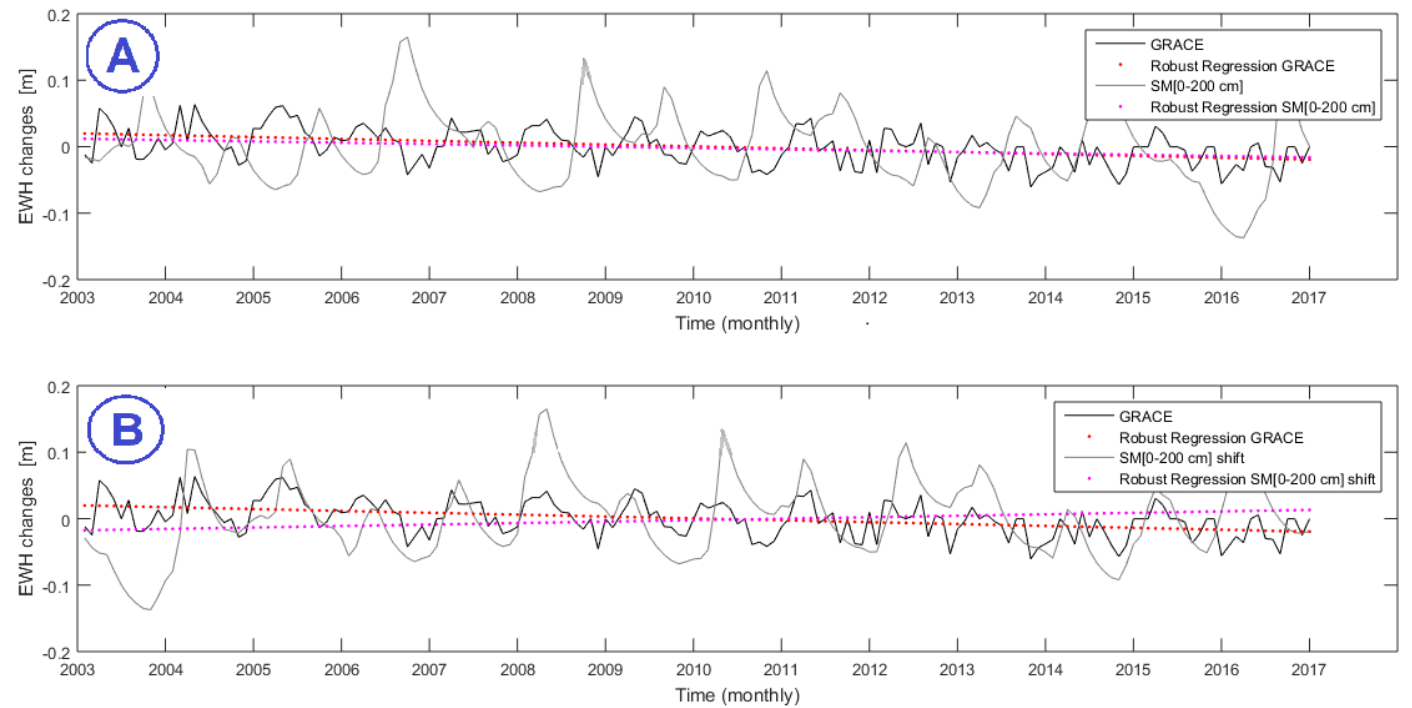

Figure 2. A) Comparison of the soil moisture content variations from GLDAS with TWS variations from GRACE during 2003-2016 in Sarakhs catchment. SM denotes soil moisture in different depths $(0-200 \mathrm{~cm})$ from GLDAS. B) Alignment of two time series using cross correlation function (Time lag= -19).

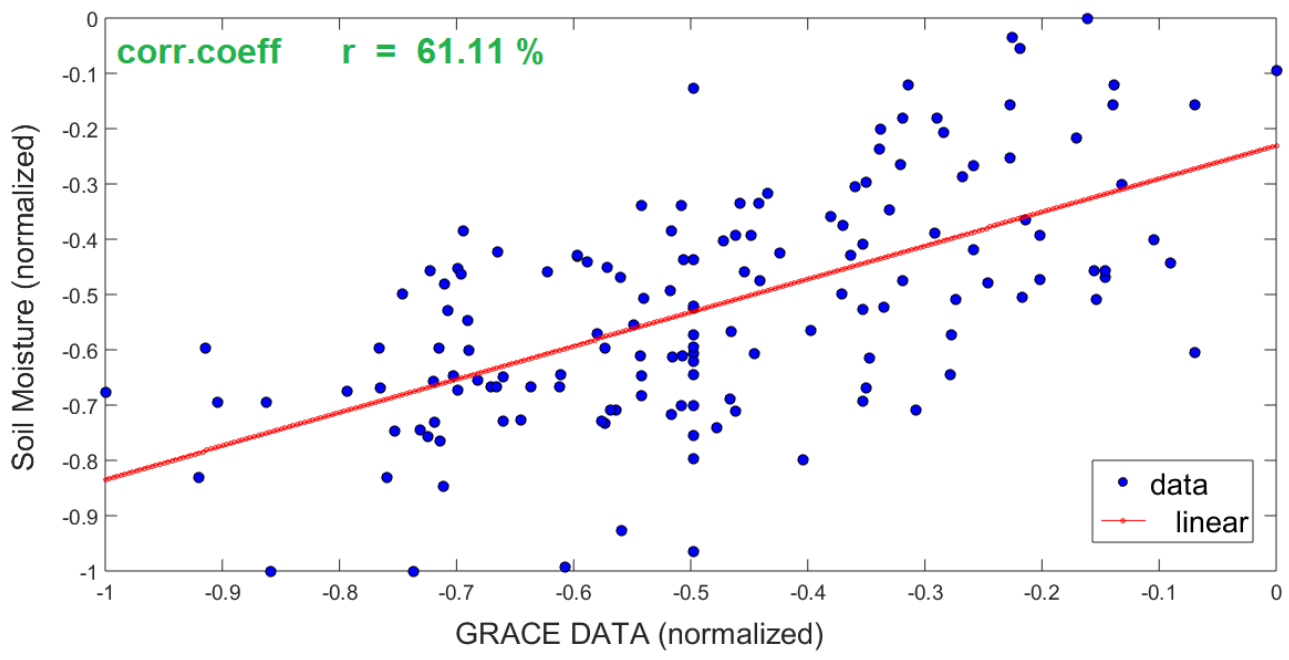

Figure 3. Comparison between average GRACE-TWS (x-axis) and the GLDAS soil moisture data (0-200 cm) (y-axis) changes axis) changes (normalized) over Sarakhs catchment from 2003 until 2016.

\section{CONCLUSION}

The occurrence of drought depends on several factors that can differ for various catchments, including reduced precipitation, increased evapotranspiration, anthropogenic activities and etc. The interpretation of the total water storage loss observed by GRACE during the study period at Sarakhs catchment can be related to many parameters. Many factors, both natural and human, can cause changes in climate. Natural factors such as precipitation and evapotranspiration have less power than anthropogenic activities on climate change. The texture and structure of soil identified in the study area (Sarakhs catchment) have a significant role in the absorption capacity and permeability of water in the soil. Therefore, access to geological maps of the area along with other sources will help to better interpret the results.

In this study, we investigate relation between GRACE TWS and soil moisture because of the soil moisture storage is a key factor in the water balance of a basin. In this region variations of soil moisture correlate strongly with changes in TWS $(>=60 \%)$. In future work, we will further investigate with other water storage compartments, in particular the groundwater in-situ information. 


\section{REFERENCES}

[1] Abelen, S., 2016. Signals of weather extremes in soil moisture and terrestrial water storage from multi-sensor Earth observations and hydrological modeling.

[2] Chen JL, Wilson CR, Famiglietti JS, Rodell M., 2007a. Attenuation effect on seasonal basin-scale water storage changes from GRACE time-variable gravity. J Geodesy. 81:237-245.

[3] https://water.fanack.com/iran/water-resources-in-iran/.

[4] Jiang, D., Wang, J., Huang, Y., Zhou, K., Ding, X., and Fu, J., 2014. The Review of GRACE Data Applications in Terrestrial Hydrology Monitoring, Advances in Meteorology, vol. 2014, Article ID 725131, 9 pages.

[5] Landerer, F. W., and Swenson, S. C., 2012. Accuracy of scaled GRACE terrestrial water storage estimates, Water Resources Research, 48(4), W04,531, doi:10.1029/2011WR011453.

[6] Seo, K. W., Wilson, C.R., Famiglietti, J.S., Chen, J.L., \& Rodell, M., 2006. Terrestrial water mass load changes from Gravity Recovery and Climate Experiment (GRACE). Water Resour. Res., 42, 15.

[7] Shulian, N., and Susaki, J., 2006. Detection of Agricultural Drought in Paddy Fields using NDVI from MODIS Data: A Case Study in Burirum Province, Thailand, 2006 IEEE International Symposium on Geoscience and Remote Sensing, Denver, CO, pp. 4076-4079.

[8] Vishwakarma, B. D., Devaraju, B., Sneeuw, N., 2016. Minimizing the effects of filtering on catchment scale GRACE solutions, Water Resources Research, 52(8), 5868-5890.

[9] Vishwakarma, B.-D., Horwath, M., Devaraju, B., Groh, A., Sneeuw, N., 2017. A Data-Driven Approach for Repairing the Hydrological Catchment Signal Damage Due to Filtering of GRACE Products, Water Resources Research, 53(11), 98249844, doi:10.1002/2017WR021150.

[10] Vishwakarma, B.D., Devaraju, B., Sneeuw, N. 2018. What Is the Spatial Resolution of GRACE Satellite Products for Hydrology? Remote Sens, 10, 852.

[11] Wang, W., Cui, W., Wang, X., \& Chen, X., 2016. Evaluation of GLDAS-1 and GLDAS-2 forcing data and Noah model simulations over China at the monthly scale. Journal of Hydrometeorology, 17(11), 2815-2833.

[12] Wilhite, D.A. and Glantz, M.H.,1985. Understanding the Drought Phenomenon: The Role of Definitions. Water International, 10, 111-120. 